British Journal of Nutrition (2020), 124, 558-566

doi:10.1017/S0007114520001397

(C) The Authors 2020. Published by Cambridge University Press. This is an Open Access article, distributed under the terms of the Creative Commons Attribution licence (http://creativecommons.org/licenses/by/4.0/), which permits unrestricted re-use, distribution, and reproduction in any medium, provided the original work is properly cited.

\title{
Maternal total energy, macronutrient and vitamin intakes during pregnancy associated with the offspring's birth size in the Japan Environment and Children's Study
}

\author{
Ehab S. Eshak ${ }^{1,2 *}$, Chika Okada ${ }^{1}$, Sachiko Baba ${ }^{3}$, Takashi Kimura ${ }^{4}$, Satoyo Ikehara ${ }^{1}$, Takuyo Sato ${ }^{5}$, \\ Kokoro Shirai ${ }^{1}$ and Hiroyasu Iso $^{1}$ for the Japan Environment and Children's Study Group \\ ${ }^{1}$ Public Health, Department of Social Medicine, Graduate School of Medicine, Osaka University, Osaka 565-0871, Japan \\ ${ }^{2}$ Department of Public Health and Preventive Medicine, Faculty of Medicine, Minia University, Minia 61511, Egypt \\ ${ }^{3}$ Bioethics and Public Policy, Department of Social Medicine, Graduate School of Medicine, Osaka University, Osaka 565-0871, \\ Japan \\ ${ }^{4}$ Department of Public Health, Hokkaido University School of Medicine, Sapporo 060-8638, Japan \\ ${ }^{5}$ Department of Maternal and Child Health Research, Division of Community Health and Research, Osaka Woman's and \\ Children's Hospital, Osaka 594-1101, Japan
}

(Submitted 6 November 2019 - Final revision received 31 March 2020 - Accepted 1 April 2020 - First published online 21 April 2020)

\section{Abstract}

Maternal diet during pregnancy can influence fetal growth; however, the available evidence is controversial. We aimed to assess whether maternal diet of Japanese women in mid-pregnancy can affect their offspring's birth size via collection of questionnaire and medical record data. The studied sample was a large cohort of paired mothers and their singleton offspring ( $n$ 78 793 ) from fifteen areas all over Japan who participated in the Japan Environment and Children's Study. The mid-pregnancy intakes of total energy, macronutrients and vitamins were lower than the recommended intakes for pregnant Japanese women. Maternal total energy intake was positively associated with the offspring's birth weight; there was a 10-g mean difference in the offspring's birth weight of mothers in the lowest (3026 g) $v$. highest (3036 g) quartiles of energy intake. Carbohydrate intake was positively associated with the offspring's birth length (mean difference of $0.7 \mathrm{~cm}$ ) and inversely associated with the ponderal index (mean difference of $0.8 \mathrm{~g} / \mathrm{cm}^{3}$ ). Offspring of mothers in the highest $v$. lowest quartiles of total dietary fibre intake were on average $9 \mathrm{~g}$ heavier and had $0.3 \mathrm{~cm}$ longer birth length and $0.2 \mathrm{~cm}$ longer head circumference. The highest in reference to lowest intake quartile of vitamin $C$ was associated with $13 \mathrm{~g}$ and $0.7 \mathrm{~cm}$ mean differences in the offspring's birth weight and length, respectively. Several other associations were evident for maternal intakes of vitamins and the offspring's birth size. In conclusion, maternal dietary intakes of energy, dietary fibre, carbohydrate and vitamins during pregnancy were associated with the offspring's birth size.

Key words: Maternal diet: Energy: Protein: Fat: Carbohydrate: Vitamins: Baby size

Optimising maternal dietary balance could be a novel appropriate approach for potential improvement of offspring's body composition $^{(1,2)}$. Maternal diet during pregnancy can influence fetal growth directly ${ }^{(3)}$ and/or indirectly through affecting maternal body weight ${ }^{(4)}$. Except for Japan, maternal obesity is rapidly increasing in the developed countries and is associated with increased offspring's birth weight ${ }^{(5)}$. In contrary, since 1970, a decreasing trend in the BMI of Japanese women was noticed $^{(6)}$, and meanwhile accompanied by almost a doublefold increase in the rate of low birth weight in the country since then ${ }^{(7)}$. In order to keep the desired lean body shape ${ }^{(8)}$, Japanese women usually adopt inappropriate diet ${ }^{(4)}$ and continue to do so even during pregnancy ${ }^{(4,9,10)}$. Dietary intakes of macro- and micronutrients among Japanese women prior to and during pregnancy were lower than the Japanese dietary references $^{(4)}$.

Previous studies that showed the association between dietary macronutrient intakes during pregnancy and birth size were inconsistent in their conclusions. Energy content ${ }^{(11-13)}$ and macronutrient intakes during pregnancy ${ }^{(4,12-14)}$ were frequently reported to be not associated with the estimated fetal body weight or birth weight. Maternal carbohydrate intake, in the Singapore Growing up towards Healthy Outcomes (GUSTO) study, was positively associated with the offspring's birth length and accordingly inversely associated with the ponderal index ${ }^{(13)}$. Other studies, however, showed that the fetal growth and birth

* Corresponding author: Dr Ehab S. Eshak fax +81-6-6879-3919, email ehab@pbhel.med.osaka-u.ac.jp 
size were inversely associated with carbohydrate intake and positively associated with protein intake in early pregnancy ${ }^{(3,15,16)}$. Intakes of total energy, protein and fat, in all trimesters of pregnancy, were positively associated with the newborn's weight in an Indian study ${ }^{(17)}$

On the other hand, dietary and supplemental vitamins are essential for the biological activity, and their status varies widely throughout pregnancy and across populations. For example, folic acid intake during pregnancy can efficiently prevent neural tube defects of the offspring ${ }^{(18)}$, while maternal intakes of $n-3$ long-chain PUFA, folic acid and vitamin D have shown potential effects on the offspring's birth weight ${ }^{(17-20)}$.

In addition to the scanty of studies that investigated maternal diet and the offspring's birth size among Japanese ${ }^{(4)}$, the available evidence has been driven from studies that included a limited number of women ${ }^{(1-4,11-20)}$. In light of previous literature, it is obvious that the relation of maternal macronutrient and vitamin intakes during pregnancy and the offspring's birth size is still unclear. Therefore, this study was conducted to investigate the prospective associations of maternal consumption of macronutrients and vitamins in early pregnancy and the offspring's birth size in a large cohort of Japanese women.

\section{Methodology}

\section{Study subjects and design}

The Japan Environment and Children's Study is a large birth cohort study that was funded by the Japan Ministry of the Environment. The detailed study protocol and methodology were described previously ${ }^{(21,22)}$. In brief, the Japan Environment and Children's Study included women during early pregnancy who were attending local governmental offices that issue pregnancy and child follow-up handbooks and/or attending obstetric facilities where pregnancy follow-up was conducted. Eventually, 103099 pregnancies from fifteen Japanese communities were registered and followed up between the years 2011 and 2014. The Japan Environment and Children's Study protocol was in full accordance with the Helsinki declaration and was reviewed and approved by the Ministry of the Environment's Institutional Review Board on Epidemiological Studies and by the Ethics Committees of all participating institutions. All subjects have given a written informed consent to participate.

\section{Diet assessment}

A $\mathrm{FFQ}^{(23)}$ was distributed during the second/third trimester to determine the usual food consumption throughout the current pregnancy, and a total of 98037 women completed this FFQ. The final sample in this analysis consisted of 78793 women, after excluding women with multiple gestations, stillbirths, abortions and maternal chronic diseases that might require nutritional therapy and those with missing nutritional or covariates data (see online Supplementary Fig. S1). A standard portion size was specified for each item of the FFQ, and the response options for the intake frequency ranged from almost never to $\geq 7$ times/d for foods and from almost never to $\geq 10$ glasses/d for beverages. The intake frequencies were multiplied by the specified portion size, and accordingly, we estimated the daily intakes of all items in the FFQ. Nutrients' contents of each food were driven from the Japanese food composition tables 5 th revised revision ${ }^{(24)}$, and the daily intakes of nutrients were calculated by summing the contents from all the food items after multiplying by the frequency of consumption.

\section{Birth size}

From the newborn medical records at birth, we obtained data about birth weight $(\mathrm{g})$, birth length, head circumference and chest circumference $(\mathrm{cm})$. All measurements were conducted by trained and experienced staffs according to the Japanese standardised manual ${ }^{(25)}$. Instructions were given to repeat the measurements for unusual measurements' values. The ponderal index was calculated from the recorded birth weight and birth length as follows: ponderal index = weight in $\mathrm{g} /$ (crown-heel length in $\mathrm{cm})^{3}$.

\section{Other covariates}

Mother and offspring's characteristics were obtained from selfadministered questionnaires that were distributed at first trimester, second/third trimesters, delivery and 1 month after delivery, and from health check-ups during pregnancy, medical records and obstetricians' data. Medical records (Dr-T1, Dr-0 $\mathrm{m}$ and Dr- $1 \mathrm{~m}$ ) transcriptions were performed by physicians, midwives/nurses and/or research coordinators. Therefore, a large bulk of information was obtained including maternal sociodemographic characteristics, lifestyle habits, in addition to medical, obstetrics and paediatric histories.

\section{Statistical analysis}

The analyses of the present study were based on the data set jecsag-20160424. Medians and interquartile ranges of the studied women's intakes of macronutrients and vitamins during pregnancy were compared with the estimated average requirement for Japanese pregnant women in the second trimester ${ }^{(26,27)}$. The proportion of women with intakes less than the estimated average requirement was given for each nutrient. The maternal and offspring's characteristics were compared among binary stratified variables of nutrients (sufficient; at least equal to the estimated average requirement $v$. insufficient; less than the estimated average requirement) using the Wilcoxon signed-rank test for continuous variables and the $\chi^{2}$ test for categorical ones. Because the distributions of the nutritional variables under study were skewed, the Kruskal-Wallis test and ANCOVA of the generalised linear modelling procedure for the log-transformed intakes of nutrients were used. Accordingly, we compared the univariate and multivariable-adjusted mean differences in the offspring's birth size indices (birth weight, birth length, head and chest circumferences and ponderal index) across the quartiles of maternal intakes of total energy, energy-adjusted (by density method) macronutrients (carbohydrate, fat, protein and total dietary fibre) and vitamins (vitamins A, K, E, D, C, B 6 , B 9 and $\mathrm{B}_{12}$ ). The geometric means of nutrients in the generalised linear modelling procedure were adjusted for maternal age (continuous), height (continuous), education (junior high/high school, 
professional/vocational school/junior college, university or higher), household income $(<2,2-<4,4-<6, \geq 6$ million Japanese yen), prepregnancy BMI $(<18.5,18 \cdot 5-<25,25-<30$ or $\left.\geq 30 \mathrm{~kg} / \mathrm{m}^{2}\right)$, net weight change during pregnancy $(<7,7-12$, $>12 \mathrm{~kg}$ ), parity $(0,1, \geq 2)$, smoking habit (never, quit before and after knowing pregnancy, current), ethanol drinking habit during pregnancy (never, former and current), mother's thyroid disease (yes or no), use of folate supplement (yes or no), offspring's sex (dichotomous) and gestational age at delivery (continuous). The median values of each nutrient intake in each quartile were used to calculate the $P_{\text {for trend }}$ across the increasing quartiles of maternal dietary intakes via the generalised linear modelling procedure. Moreover, linear regression analyses were conducted to estimate the changes in the offspring's birth size parameters with 1-SD increment of maternal macronutrients intakes. Probability values for statistical tests were two-tailed, and $P<0.05$ was regarded as statistically significant with at least $80 \%$ statistical power for testing. The SAS statistical package (version 9.4, SAS) was used for the analyses.

\section{Results}

The main characteristics of the studied 78793 pregnant Japanese women are given in Table 1. Macronutrient and vitamin intakes of the studied women were, in general, lower than the dietary recommended intakes for pregnant Japanese women (Table 2); the proportion of participants with intakes lower than the dietary recommended intakes ranged from $22.1 \%$ for fat intake to $92.4 \%$ for protein intake.

In comparison with the proportions in the insufficient intake groups, the proportions of older women were higher in the sufficient intake group of all nutrients, except for carbohydrate. The proportions of highly educated women (university or higher) were higher, while the proportions of smoking women were lower in the sufficient $v$. insufficient intake groups of all nutrients, except for energy and carbohydrate. The proportions of alcohol users were higher in the sufficient intake group when compared with the insufficient intake group of most nutrients, except for carbohydrate. The proportions of nulliparous women and women who gained $<7.0 \mathrm{~kg}$ during the pregnancy were lower in the sufficient $v$. insufficient intake groups for all nutrients, except for carbohydrate and fat. The mean gestational age of the offspring was lower in the sufficient than that in the insufficient intake groups of dietary variables, except for carbohydrate, fat and vitamin C (Table 3).

There were significant increases in the offspring's mean birth weight, birth length, head circumference and chest circumference and decreases in the mean ponderal index across the increasing quartiles of maternal dietary intakes of energy, total fibre and the most studied vitamins (online Supplementary Tables S1 and S2). After adjusting for maternal and offspring's characteristics, there was $10 \mathrm{~g}$ increment in the birth weight of offspring born to mothers in the highest $v$. lowest quartiles of total energy intake. Women in the highest $v$. those in the lowest quartiles of dietary fibre intake gave birth to on average $9 \mathrm{~g}$ heavier and $0.3 \mathrm{~cm}$ taller babies. Maternal carbohydrate intake was positively associated with the offspring's birth length and inversely associated with the ponderal index; fat intake was also
Table 1. Main characteristics of the studied mothers (Mean values and standard deviations; numbers and percentages)

\begin{tabular}{|c|c|c|}
\hline Characteristics & $n$ & $\%$ \\
\hline \multicolumn{3}{|l|}{ Age (years) } \\
\hline Mean & \multicolumn{2}{|c|}{$31 \cdot 0$} \\
\hline SD & \multicolumn{2}{|c|}{$5 \cdot 0$} \\
\hline \multicolumn{3}{|l|}{ Education level } \\
\hline Junior high/high school & 28540 & $36 \cdot 2$ \\
\hline $\begin{array}{l}\text { Higher professional school/vocational school/ } \\
\text { junior college }\end{array}$ & 32767 & 41.6 \\
\hline University/graduate school & 17200 & $21 \cdot 8$ \\
\hline Missing & 286 & 0.4 \\
\hline \multicolumn{3}{|l|}{ Smoking } \\
\hline Never & 46062 & $58 \cdot 5$ \\
\hline Former & 28673 & $36 \cdot 4$ \\
\hline Current & 3397 & $4 \cdot 3$ \\
\hline Missing & 661 & 0.8 \\
\hline \multicolumn{3}{|l|}{ Alcohol drinking } \\
\hline Never & 26622 & 33.8 \\
\hline Former & 49517 & $62 \cdot 8$ \\
\hline Current & 2123 & $2 \cdot 7$ \\
\hline Missing & 531 & 0.7 \\
\hline \multicolumn{3}{|l|}{ Parity } \\
\hline 0 & 31219 & 39.6 \\
\hline 1 & 29831 & 37.9 \\
\hline$\geq 2$ & 15887 & $20 \cdot 2$ \\
\hline $\bar{M}$ Missing & 1856 & 2.4 \\
\hline \multicolumn{3}{|l|}{ Household annual income (million Japanese yen) } \\
\hline$<2$ & 4162 & $5 \cdot 3$ \\
\hline $2-<4$ & 25494 & $32 \cdot 4$ \\
\hline $4-<6$ & 24219 & $30 \cdot 7$ \\
\hline$\geq 6$ & 19472 & 24.7 \\
\hline Missing & 5446 & $6 \cdot 9$ \\
\hline \multicolumn{3}{|l|}{ Prepregnancy BMI $\left(\mathrm{kg} / \mathrm{m}^{2}\right)$} \\
\hline$<18.5$ & 12744 & $16 \cdot 2$ \\
\hline $18 \cdot 5-<25$ & 58160 & 73.8 \\
\hline $25-<30$ & 6126 & $7 \cdot 8$ \\
\hline$\geq 30$ & 1763 & $2 \cdot 2$ \\
\hline \multicolumn{3}{|l|}{ Hyperthyroidism } \\
\hline Yes & 769 & 1.0 \\
\hline No & 77591 & 98.5 \\
\hline Missing & 433 & 0.5 \\
\hline \multicolumn{3}{|l|}{ Hypothyroidism } \\
\hline Yes & 695 & 0.9 \\
\hline No & 77665 & 98.6 \\
\hline Missing & 433 & 0.5 \\
\hline \multicolumn{3}{|l|}{ Folate supplement use } \\
\hline None & 45747 & $58 \cdot 1$ \\
\hline Once/month & 1821 & $2 \cdot 3$ \\
\hline 2-3 times/month & 3972 & $5 \cdot 0$ \\
\hline 1-3 times/week & 6391 & 8.1 \\
\hline 4-6 times/week & 4348 & $5 \cdot 5$ \\
\hline Once/d & 15320 & $19 \cdot 4$ \\
\hline$\geq 2$ times/d & 983 & $1 \cdot 2$ \\
\hline Missing & 211 & 0.3 \\
\hline \multicolumn{3}{|l|}{ Offspring's sex of current pregnancy } \\
\hline Male & 40414 & $51 \cdot 3$ \\
\hline Female & 38379 & 48.7 \\
\hline \multicolumn{3}{|c|}{ Gestational age of the offspring of current pregnancy (weeks) } \\
\hline Mean & & \\
\hline SD & & \\
\hline
\end{tabular}

inversely associated with the ponderal index, whereas protein intake was not associated with birth size (Table 4). One-sD increment in maternal energy intake was associated with $3.3 \mathrm{~g}$ increment in birth weight and $0.1 \mathrm{~cm}$ increment in chest circumference of the offspring. There were about $0.2 \mathrm{~cm}$ increments in birth length with 1-sD increment of \%E from both carbohydrate 
Table 2. During pregnancy intakes of energy, macronutrients and vitamins of the studied mothers $(n 78793)^{\star}$

(Median values and interquartile ranges (IQR); numbers and percentages)

\begin{tabular}{|c|c|c|c|c|c|}
\hline & \multirow[b]{2}{*}{ Median } & \multirow[b]{2}{*}{ IQR } & \multirow{2}{*}{$\begin{array}{l}\text { Estimated average requirement } \\
\text { for Japanese pregnant women in } \\
\text { the second trimester }\end{array}$} & \multicolumn{2}{|c|}{$\begin{array}{l}<\text { Estimated average } \\
\text { requirement }\end{array}$} \\
\hline & & & & $n$ & $\%$ \\
\hline Energy $(\mathrm{kcal} / \mathrm{d}) \dagger$ & 1620 & $1311-2015$ & $2200(2500)$ & 66138 & 83.9 \\
\hline \multicolumn{6}{|l|}{ Macronutrients } \\
\hline Carbohydrate (g/d) & $223 \cdot 8$ & $182 \cdot 6-272 \cdot 4$ & & & \\
\hline Carbohydrate (\%E) & $55 \cdot 3$ & $50 \cdot 2-60 \cdot 3$ & $57.5 \% \mathrm{E}$ as desired goal & 48761 & 61.9 \\
\hline Fat $(\mathrm{g} / \mathrm{d})$ & $53 \cdot 2$ & $39 \cdot 3-71 \cdot 3$ & & & \\
\hline Fat (\%E) & 29.8 & $25 \cdot 6-34 \cdot 1$ & $25 \% \mathrm{E}$ as desired goal & 17419 & $22 \cdot 1$ \\
\hline Protein (g/d) & $54 \cdot 3$ & $42 \cdot 2-70 \cdot 2$ & 45 & 24026 & $30 \cdot 5$ \\
\hline Protein (\%E) & $13 \cdot 5$ & $12 \cdot 2-14 \cdot 8$ & $16.5 \% \mathrm{E}$ as desired goal & 72802 & $92 \cdot 4$ \\
\hline Total dietary fibre (g/d) & 9.6 & $7 \cdot 1-12 \cdot 9$ & $\geq 18$ & 72241 & 91.7 \\
\hline \multicolumn{6}{|l|}{ Vitamins } \\
\hline Vitamin A ( $\mu \mathrm{g} / \mathrm{d})$ & 404 & $265-631$ & 500 & 49600 & $62 \cdot 9$ \\
\hline Vitamin K ( $\mu \mathrm{g} / \mathrm{d})$ & 155 & $102-238$ & $150 \ddagger$ & 37497 & $47 \cdot 6$ \\
\hline Vitamin E (mg/d) & 5.7 & $4 \cdot 2-7 \cdot 7$ & $6.5 \ddagger$ & 47655 & $60 \cdot 5$ \\
\hline Vitamin D ( $\mu \mathrm{g} / \mathrm{d})$ & 3.9 & $2 \cdot 3-6 \cdot 1$ & $8.5 \ddagger$ & 68722 & $87 \cdot 2$ \\
\hline Vitamin C (mg/d) & 74 & 48-109 & 95 & 52497 & $66 \cdot 6$ \\
\hline Vitamin $B_{6}(\mathrm{mg} / \mathrm{d})$ & 0.93 & $0.71-1.22$ & $1 \cdot 2$ & 57800 & 73.4 \\
\hline Folate $(\mu \mathrm{g} / \mathrm{d})$ & 229 & $166-312$ & 400 & 69524 & 88.2 \\
\hline Vitamin $B_{12}(\mu \mathrm{g} / \mathrm{d})$ & 3.5 & $2 \cdot 2-5 \cdot 4$ & $2 \cdot 3$ & 20550 & $26 \cdot 1$ \\
\hline
\end{tabular}

$\% \mathrm{E}$, proportion of individual energy intakes using the following energy-conversion value; protein $=4 \mathrm{kcal} / \mathrm{g}$, fat $=9 \mathrm{kcal} / \mathrm{g}$ and carbohydrate $=4 \mathrm{kcal} / \mathrm{g}$

* Intakes were estimated from the FFQ during the second trimester.

† To convert energy values from kcal to kJ multiply by $4 \cdot 184$.

$\ddagger$ Express adequate intake, where estimated average requirement could not be set due to insufficient scientific evidence.

and total dietary fibre, whereas the $0 \cdot 2 \mathrm{~cm}$ decrement in birth length was observed for 1-sD increment in \%E from fat (data not shown in tables). As shown in Table 5, the intakes of fat-soluble vitamins, vitamin $\mathrm{C}$ and folate were associated with the offspring's birth weight. Maternal intakes of vitamins $\mathrm{C}, \mathrm{D}, \mathrm{K}, \mathrm{B}_{6}, \mathrm{~B}_{12}$ and folate were associated with their babies' birth length; vitamins $\mathrm{A}, \mathrm{E}$ and $\mathrm{D}$ intakes were associated with head circumference; vitamins A, C and D intakes were associated with chest circumference, whereas intakes of vitamin $\mathrm{K}$ were inversely associated with the ponderal index of the offspring.

\section{Discussion}

In this large cohort of Japanese women, maternal dietary intakes of total energy, macronutrients and vitamins were associated with the offspring's birth size. Meanwhile, these intakes were lower than the dietary recommended intakes for pregnant Japanese women.

Our findings that Japanese pregnant women tended to have dietary intakes lower than the RDI are matching results of previous studies ${ }^{(4,9,10)}$. Japanese women keenness to keep a thin body ${ }^{(8)}$ together with their strict adherence to the nutritional guidelines for weight control during pregnancy ${ }^{(28)}$ could be possible explanations of the findings of the current research.

Findings from the previous literature were a mix of discrepancies regarding the associations between maternal nutrition during pregnancy and the offspring's birth size $\mathrm{e}^{(1-4,11-20,29-32)}$. However, those studies that reported maternal dietary intakes during pregnancy to be associated with the offspring's birth size justified their findings by two pathways: indirect effects through the changes in the maternal body weight ${ }^{(2,4,13,15,16,29)}$ and direct effects of maternal dietary intakes on the fetal growth and body composition $^{(1-3,11,12)}$.

In contrary to our findings, many studies have shown no associations between the mother's energy content intake and the newborn's birth size ${ }^{(4,11-14)}$, and one study has reported an inverse association with neonatal abdominal obesity ${ }^{(1)}$. However, the positive association between maternal total energy intake and the offspring's birth weight in our study is matching those reported in a few previous studies ${ }^{(17,33)}$. This could be justified by the fact that with the additional need for extra energy content during pregnancy for placental and fetal growths, the low mean energy intake of Japanese pregnant women (lower than RDI) could be under the threshold of energy intake that might be associated inversely with the offspring's birth size.

High maternal intakes of carbohydrate were positively associated with the offspring's birth length, and none of carbohydrate, fat or protein intakes was associated with the birth weight of the offspring in the multivariable-adjusted analysis of the current study. In a study of multi-ethnic Asian population, the addition of carbohydrate in non-energetic addition models and the substitution of carbohydrate for protein in energetic substitution models were positively associated with the newborn's birth length, and there were no associations of carbohydrate, fat or protein intakes with the birth weight ${ }^{(13)}$. The majority of the previous studies showed no associations of both carbohydrate and fat intakes during pregnancy with birth weight $^{(4,11,12,14)}$ and head circumference ${ }^{(14)}$ of the newborn. However, positive associations were also documented in some other studies ${ }^{(13,17,29,30)}$. In contrary, one Japanese study showed that dietary patterns during pregnancy rich in bread, soft drinks and confectioneries and low in vegetables and fish have inverse associations with the baby's birth weight ${ }^{(34)}$. 
Table 3. Maternal and offspring's characteristics according to maternal intakes of energy, macronutrients and vitamins during pregnancy (Mean values and percentages)

\begin{tabular}{|c|c|c|c|c|c|c|c|c|c|c|c|c|}
\hline & \multicolumn{10}{|c|}{ Maternal } & & \\
\hline & \multirow{2}{*}{$\begin{array}{c}\text { Mean } \\
\text { age } \\
\text { (years) }\end{array}$} & \multirow{2}{*}{$\begin{array}{c}\text { Highly } \\
\text { educated } \\
(\%)\end{array}$} & \multirow[b]{2}{*}{$\begin{array}{c}\text { Smoker } \\
(\%)\end{array}$} & \multirow{2}{*}{$\begin{array}{c}\text { Alcohol } \\
\text { user } \\
(\%)\end{array}$} & \multicolumn{3}{|c|}{ Parity (\%) } & \multicolumn{3}{|c|}{ Pregnancy weight gain (\%) } & \multicolumn{2}{|c|}{ Offspring } \\
\hline & & & & & 0 & 1 & $\geq 2$ & $<7 \mathrm{~kg}$ & $7-12 \mathrm{~kg}$ & $\geq 12 \mathrm{~kg}$ & $\begin{array}{l}\text { Offspring } \\
\text { boy (\%) }\end{array}$ & $\begin{array}{l}\text { Gestational } \\
\text { age (weeks) }\end{array}$ \\
\hline \multicolumn{13}{|l|}{ Energy } \\
\hline $\begin{array}{l}\text { Sufficient } \\
\quad(2500 \mathrm{kcal})\end{array}$ & $31.4 \ddagger$ & $20 \cdot 4 \ddagger$ & $5 \cdot 0 \ddagger$ & $3 \cdot 2 \ddagger$ & 31.7 & $41 \cdot 0$ & $25 \cdot 4 \ddagger$ & $14 \cdot 6$ & $49 \cdot 2$ & $34.5 \ddagger$ & $51 \cdot 1$ & $38.82 \ddagger$ \\
\hline Insufficient & 30.9 & $22 \cdot 1$ & $4 \cdot 2$ & $2 \cdot 6$ & $41 \cdot 1$ & $37 \cdot 3$ & $19 \cdot 2$ & $16 \cdot 3$ & $52 \cdot 4$ & $29 \cdot 3$ & $51 \cdot 3$ & 38.89 \\
\hline \multicolumn{13}{|l|}{ Macronutrients } \\
\hline Sufficient $(57.5 \%)$ & $30 \cdot 8 \ddagger$ & $18 \cdot 8 \ddagger$ & $4.8 \ddagger$ & $2 \cdot 3 \ddagger$ & $39 \cdot 7$ & $37 \cdot 7$ & $20 \cdot 4$ & $16 \cdot 4$ & $51 \cdot 1$ & $30 \cdot 8 \ddagger$ & $51 \cdot 2$ & 38.87 \\
\hline Insufficient & $31 \cdot 1$ & $23 \cdot 7$ & 4.0 & $2 \cdot 9$ & 39.6 & $38 \cdot 0$ & $20 \cdot 0$ & $15 \cdot 8$ & $52 \cdot 4$ & $29 \cdot 7$ & $51 \cdot 3$ & 38.87 \\
\hline \multicolumn{13}{|l|}{ Fat $(\% \mathrm{E})$} \\
\hline Sufficient (25\%) & $31 \cdot 1 \ddagger$ & $23 \cdot 2 \ddagger$ & $4.0 \ddagger$ & $2 \cdot 7 \ddagger$ & $39 \cdot 8$ & $37 \cdot 9$ & $19.9 \dagger$ & $15 \cdot 8$ & $52 \cdot 3$ & $29.8 \ddagger$ & 51.4 & $38.88 \ddagger$ \\
\hline Insufficient & $30 \cdot 7$ & $17 \cdot 0$ & 5.5 & $2 \cdot 8$ & $39 \cdot 0$ & $37 \cdot 8$ & $21 \cdot 0$ & $16 \cdot 8$ & $50 \cdot 5$ & $31 \cdot 1$ & $51 \cdot 0$ & 38.86 \\
\hline \multicolumn{13}{|l|}{ Protein (\%E) } \\
\hline Sufficient (16.5\%) & $31.4 \ddagger$ & $23 \cdot 8 \ddagger$ & $3.8 \ddagger$ & $2 \cdot 8 \ddagger$ & $37 \cdot 0$ & 39.5 & $21 \cdot 3 \ddagger$ & $15 \cdot 4$ & $52 \cdot 2$ & $30 \cdot 3 \ddagger$ & $51 \cdot 2$ & $38.86 \ddagger$ \\
\hline Insufficient & $30 \cdot 1$ & $17 \cdot 4$ & $5 \cdot 4$ & $2 \cdot 4$ & $45 \cdot 7$ & $34 \cdot 1$ & $17 \cdot 5$ & $17 \cdot 4$ & $51 \cdot 2$ & $29 \cdot 7$ & $51 \cdot 4$ & 38.90 \\
\hline \multicolumn{13}{|l|}{ Total dietary fibre } \\
\hline Sufficient (18 g) & $32 \cdot 2 \ddagger$ & $23.4 \ddagger$ & $3 \cdot 2 \ddagger$ & $3.0 \ddagger$ & $29 \cdot 6$ & $42 \cdot 2$ & $26 \cdot 2 \ddagger$ & $16 \cdot 3$ & $50 \cdot 8$ & $31 \cdot 2$ & $50 \cdot 8$ & $38 \cdot 81$ \\
\hline Insufficient & $30 \cdot 9$ & $21 \cdot 7$ & $4 \cdot 4$ & $2 \cdot 7$ & $40 \cdot 5$ & $37 \cdot 5$ & $19 \cdot 6$ & $16 \cdot 0$ & $52 \cdot 0$ & $30 \cdot 0$ & $51 \cdot 3$ & $38 \cdot 88$ \\
\hline \multicolumn{13}{|l|}{ Vitamins } \\
\hline \multicolumn{13}{|l|}{ Vitamin A } \\
\hline Sufficient $(500 \mu \mathrm{g})$ & $31 \cdot 6 \ddagger$ & $25 \cdot 3 \ddagger$ & $3 \cdot 7 \ddagger$ & $3.0 \ddagger$ & $34 \cdot 2$ & $40 \cdot 8$ & $22 \cdot 9 \ddagger$ & $15 \cdot 7$ & $52 \cdot 5$ & $29 \cdot 8 \ddagger$ & $51 \cdot 3$ & $38 \cdot 86 \ddagger$ \\
\hline Insufficient & 30.6 & $19 \cdot 8$ & $4 \cdot 6$ & $2 \cdot 5$ & $42 \cdot 8$ & $36 \cdot 1$ & 18.5 & $16 \cdot 2$ & $51 \cdot 6$ & 30.3 & $51 \cdot 3$ & $38 \cdot 88$ \\
\hline \multicolumn{13}{|l|}{ Vitamin $\mathrm{K}$} \\
\hline Sufficient $(150 \mu \mathrm{g})$ & $31.6 \ddagger$ & 24.3‡ & $3.4 \ddagger$ & $2.8 \dagger$ & $36 \cdot 5$ & 39.9 & $21.5 \ddagger$ & $15 \cdot 9$ & $52 \cdot 6$ & $29.5 \ddagger$ & $51 \cdot 2$ & $38.86 \dagger$ \\
\hline Insufficient & $30 \cdot 4$ & $19 \cdot 1$ & $5 \cdot 3$ & 2.5 & $43 \cdot 1$ & $35 \cdot 7$ & $18 \cdot 7$ & $16 \cdot 2$ & $51 \cdot a 2$ & $30 \cdot 8$ & $51 \cdot 4$ & 38.89 \\
\hline \multicolumn{13}{|l|}{ Vitamin E } \\
\hline Sufficient (6 mg) & $31 \cdot 7 \ddagger$ & $24 \cdot 7 \ddagger$ & $3 \cdot 6 \ddagger$ & $3.0 \dagger$ & $35 \cdot 6$ & $40 \cdot 3$ & $21.9 \ddagger$ & $15 \cdot 4$ & $52 \cdot 0$ & $30 \cdot 5 \ddagger$ & 51.4 & $38.86 \ddagger$ \\
\hline Insufficient & 30.5 & $20 \cdot 0$ & $4 \cdot 8$ & 2.5 & $42 \cdot 2$ & $36 \cdot 3$ & 19.0 & $16 \cdot 4$ & $51 \cdot 8$ & 29.9 & $51 \cdot 3$ & 38.89 \\
\hline \multicolumn{13}{|l|}{ Vitamin D } \\
\hline Sufficient $(5.5 \mu \mathrm{g})$ & $31.5 \ddagger$ & $22 \cdot 6^{*}$ & $3 \cdot 9^{*}$ & $2 \cdot 9$ & 31.4 & $42 \cdot 8$ & $23.6 \ddagger$ & $16 \cdot 3$ & $51 \cdot 6$ & $30 \cdot 1$ & 51.4 & $38.83 \ddagger$ \\
\hline Insufficient & 30.9 & $21 \cdot 7$ & $4 \cdot 4$ & $2 \cdot 7$ & $40 \cdot 8$ & $37 \cdot 1$ & $19 \cdot 7$ & $16 \cdot 0$ & $52 \cdot 0$ & $30 \cdot 1$ & $51 \cdot 3$ & 38.88 \\
\hline \multicolumn{13}{|l|}{ Vitamin C } \\
\hline Sufficient (95 mg) & $31.6 \ddagger$ & $25.0 \ddagger$ & $3 \cdot 2 \ddagger$ & $2 \cdot 7$ & $36 \cdot 7$ & 39.9 & $21 \cdot 2 \ddagger$ & $15 \cdot 7$ & $52 \cdot 2$ & $30 \cdot 4 \ddagger$ & 51.4 & $38 \cdot 87$ \\
\hline Insufficient & $30 \cdot 7$ & $20 \cdot 2$ & 4.9 & $2 \cdot 7$ & $41 \cdot 1$ & $36 \cdot 8$ & 19.6 & $16 \cdot 2$ & $51 \cdot 8$ & $30 \cdot 0$ & $51 \cdot 3$ & 38.88 \\
\hline \multicolumn{13}{|l|}{ Vitamin $\mathrm{B}_{6}$} \\
\hline Sufficient (1.2 mg) & $31 \cdot 7 \ddagger$ & $25 \cdot 0 \ddagger$ & $3.5 \ddagger$ & $3.0 \ddagger$ & $34 \cdot 1$ & $41 \cdot 1$ & $22 \cdot 7 \ddagger$ & $15 \cdot 4$ & $52 \cdot 1$ & $30 \cdot 5 \ddagger$ & $51 \cdot 2$ & $38.85 \ddagger$ \\
\hline Insufficient & $30 \cdot 7$ & $20 \cdot 7$ & $4 \cdot 6$ & $2 \cdot 6$ & $41 \cdot 6$ & $36 \cdot 7$ & $19 \cdot 2$ & $16 \cdot 2$ & $51 \cdot 8$ & 30.0 & $51 \cdot 3$ & 38.88 \\
\hline Folate & & & & & & & & & & & & \\
\hline Sufficient $(400 \mu \mathrm{g})$ & $31.9 \ddagger$ & $23 \cdot 1 \dagger$ & $3 \cdot 9^{*}$ & $3 \cdot 1^{*}$ & 31.4 & $41 \cdot 6$ & $24.9 \ddagger$ & $16 \cdot 3$ & $51 \cdot 3$ & $30 \cdot 7 \ddagger$ & $51 \cdot 3$ & $38.83 \ddagger$ \\
\hline Insufficient & 30.9 & $21 \cdot 7$ & $4 \cdot 4$ & $2 \cdot 6$ & $40 \cdot 7$ & $37 \cdot 4$ & 19.5 & $16 \cdot 0$ & $52 \cdot 0$ & $30 \cdot 0$ & $51 \cdot 3$ & $38 \cdot 88$ \\
\hline Vitamin $\mathrm{B}_{12}$ & & & & & & & & & & & & \\
\hline Sufficient $(2.3 \mu \mathrm{g})$ & $31 \cdot 3 \ddagger$ & $23.4 \ddagger$ & $4 \cdot 1 \ddagger$ & $2.9 \ddagger$ & $37 \cdot 2$ & 39.4 & $21 \cdot 1 \ddagger$ & $15 \cdot 9$ & $52 \cdot 3$ & $29 \cdot 7 \ddagger$ & $51 \cdot 3$ & $38.86 \ddagger$ \\
\hline Insufficient & $30 \cdot 2$ & $17 \cdot 4$ & $5 \cdot 0$ & $2 \cdot 2$ & $46 \cdot 4$ & 33.5 & $17 \cdot 6$ & $16 \cdot 4$ & $50 \cdot 7$ & 31.2 & $51 \cdot 3$ & 38.91 \\
\hline
\end{tabular}

The Wilcoxon rank-sum test and the $\chi^{2}$ test were used to compare between sufficient and insufficient groups for continuous and categorical variables, respectively ${ }^{\star} P<0.05$, $\dagger P<0.001, \ddagger P<0.001)$.

$\S$ To convert energy values from kcal to kJ multiply by $4 \cdot 184$.

The association between protein intake of mothers and the offspring's birth size lost its significance in the multivariable-adjusted model. Some of the released investigations reported positive associations of the mother's protein intake with birth weight $^{(2,15,17,29,33)}$, inverse associations with birth weight ${ }^{(16)}$ and birth length ${ }^{(13)}$, and no association ${ }^{(4,12-14)}$ with birth weight of the offspring.

Optimal dietary fibre intake during pregnancy is important for both the mother's health and fetal growth ${ }^{(35)}$. Higher intakes of insoluble dietary fibre by pregnant Chinese women were positively associated with their offspring's birth weight ${ }^{(35)}$. Our study is the first, up to our knowledge, to investigate and to show positive associations between maternal intakes of dietary fibre and the offspring's birth weight, birth length, head circumference and inverse associations with the ponderal index.

The positive associations between maternal dietary intakes of most studied vitamins with the offspring's birth size in our study are matching the findings from some previous reports. Maternal intakes of vitamin D and folic acid were positively associated with the birth weight ${ }^{(17-19,31,36)}$. Vitamin C intake in early pregnancy was the only nutrient to show a positive association with birth weight in prospective studies in south England ${ }^{(12)}$ and China ${ }^{(36)}$. Folate dietary intakes, measured at several occasions during pregnancy, were positively associated with the birth weight in an Indian study ${ }^{(17)}$, while folate supplementation during pregnancy was positively associated with birth weight but 
Table 4. Associations of maternal intakes of energy and macronutrients during pregnancy with the offspring's birth size* (Mean values with their standard errors)

\begin{tabular}{|c|c|c|c|c|c|c|c|c|c|c|c|c|c|}
\hline & \multicolumn{12}{|c|}{ Quartiles of energy and macronutrient intakes } & \multirow[b]{3}{*}{$P_{\text {trend }}$} \\
\hline & \multicolumn{3}{|c|}{ Q1 } & \multicolumn{3}{|c|}{ Q2 } & \multicolumn{3}{|c|}{ Q3 } & \multicolumn{3}{|c|}{ Q4 } & \\
\hline & Mean & & SE & Mean & & SE & Mean & & SE & Mean & & SE & \\
\hline Energy (kcal†) & 1075 & & & 1466 & & & 1800 & & & 2650 & & & \\
\hline No. of participants & & 19716 & & & 19654 & & & 19736 & & & 19687 & & \\
\hline Birth weight (g) & 3026 & & $2 \cdot 0$ & 3031 & & $2 \cdot 0$ & 3036 & & $2 \cdot 0$ & 3036 & & $2 \cdot 0$ & 0.004 \\
\hline Birth length (cm) & 48.94 & & 0.01 & 48.96 & & 0.01 & 48.97 & & 0.01 & 48.97 & & 0.01 & 0.41 \\
\hline Head circumference $(\mathrm{cm})$ & 33.18 & & 0.01 & 33.19 & & 0.01 & 33.19 & & 0.01 & 33.20 & & 0.01 & 0.34 \\
\hline Chest circumference $(\mathrm{cm})$ & $31 \cdot 77$ & & 0.01 & 31.78 & & 0.01 & 31.79 & & 0.01 & $31 \cdot 81$ & & 0.01 & 0.11 \\
\hline Ponderal index $\left(\mathrm{kg} / \mathrm{m}^{3}\right)$ & $25 \cdot 76$ & & 0.02 & $25 \cdot 78$ & & 0.02 & $25 \cdot 79$ & & 0.02 & $25 \cdot 82$ & & 0.02 & 0.17 \\
\hline Macronutrients & & & & & & & & & & & & & \\
\hline Carbohydrate (\%E) & $45 \cdot 1$ & & & 52.9 & & & 57.7 & & & 64.9 & & & \\
\hline No. of participants & & 19698 & & & 19698 & & & 19699 & & & 19698 & & \\
\hline Birth weight (g) & 3030 & & $2 \cdot 0$ & 3031 & & $2 \cdot 0$ & 3037 & & $2 \cdot 0$ & 3030 & & 0.20 & 0.07 \\
\hline Birth length $(\mathrm{cm})$ & 48.93 & & 0.01 & 48.95 & & 0.01 & 48.96 & & 0.01 & $49 \cdot 00$ & & 0.01 & 0.002 \\
\hline Head circumference $(\mathrm{cm})$ & 33.20 & & 0.01 & 33.19 & & 0.01 & $33 \cdot 19$ & & 0.01 & 33.19 & & 0.01 & 0.92 \\
\hline Chest circumference $(\mathrm{cm})$ & 31.79 & & 0.01 & 31.78 & & 0.01 & 31.79 & & 0.01 & 31.78 & & 0.01 & 0.85 \\
\hline Ponderal index $\left(\mathrm{kg} / \mathrm{m}^{3}\right)$ & $25 \cdot 84$ & & 0.02 & $25 \cdot 78$ & & 0.02 & $25 \cdot 78$ & & 0.02 & $25 \cdot 76$ & & 0.02 & 0.02 \\
\hline Fat $(\% \mathrm{E})$ & $21 \cdot 7$ & & & 27.8 & & & 31.8 & & & $38 \cdot 3$ & & & \\
\hline No. of participants & & 19698 & & & 19697 & & & 19700 & & & 19698 & & \\
\hline Birth weight (g) & 3032 & & $2 \cdot 0$ & 3035 & & $2 \cdot 0$ & 3033 & & $2 \cdot 0$ & 3030 & & 0.20 & 0.58 \\
\hline Birth length (cm) & 48.98 & & 0.01 & 48.97 & & 0.01 & 48.95 & & 0.01 & 48.94 & & 0.01 & 0.10 \\
\hline Head circumference $(\mathrm{cm})$ & 33.19 & & 0.01 & 33.19 & & 0.01 & $33 \cdot 19$ & & 0.01 & $33 \cdot 19$ & & 0.01 & 0.98 \\
\hline Chest circumference $(\mathrm{cm})$ & $31 \cdot 78$ & & 0.01 & 31.79 & & 0.01 & 31.79 & & 0.01 & 31.80 & & 0.01 & 0.73 \\
\hline Ponderal index $\left(\mathrm{kg} / \mathrm{m}^{3}\right)$ & $25 \cdot 75$ & & 0.02 & $25 \cdot 79$ & & 0.02 & $25 \cdot 80$ & & 0.02 & $25 \cdot 82$ & & 0.02 & 0.05 \\
\hline Protein (\%E) & 11.1 & & & $12 \cdot 9$ & & & 14.1 & & & $16 \cdot 2$ & & & \\
\hline No. of participants & & 19698 & & & 19697 & & & 19700 & & & 19698 & & \\
\hline Birth weight (g) & 3028 & & $2 \cdot 0$ & 3035 & & $2 \cdot 0$ & 3034 & & $2 \cdot 0$ & 3032 & & $2 \cdot 0$ & 0.21 \\
\hline Birth length (cm) & 48.95 & & 0.01 & 48.97 & & 0.01 & 48.98 & & 0.01 & 48.94 & & 0.01 & 0.12 \\
\hline Head circumference $(\mathrm{cm})$ & $33 \cdot 18$ & & 0.01 & 33.19 & & 0.01 & 33.20 & & 0.01 & $33 \cdot 20$ & & 0.01 & 0.55 \\
\hline Chest circumference $(\mathrm{cm})$ & 31.79 & & 0.01 & 31.79 & & 0.01 & 31.78 & & 0.01 & 31.79 & & 0.01 & 0.75 \\
\hline Ponderal index $\left(\mathrm{kg} / \mathrm{m}^{3}\right)$ & $25 \cdot 78$ & & 0.02 & $25 \cdot 79$ & & 0.02 & 25.77 & & 0.02 & $25 \cdot 82$ & & 0.02 & 0.23 \\
\hline Total dietary fibre ( $\mathrm{g} / 1000 \mathrm{kcal})$ & 3.9 & & & $5 \cdot 3$ & & & 6.5 & & & $8 \cdot 7$ & & & \\
\hline No. of participants & & 19698 & & & 19698 & & & 19699 & & & 19698 & & \\
\hline Birth weight (g) & 3026 & & $2 \cdot 0$ & 3034 & & $2 \cdot 0$ & 3034 & & $2 \cdot 0$ & 3035 & & $2 \cdot 0$ & 0.02 \\
\hline Birth length (cm) & $48 \cdot 89$ & & 0.01 & 48.97 & & 0.01 & $48 \cdot 97$ & & 0.01 & 49.01 & & 0.01 & $<0.001$ \\
\hline Head circumference $(\mathrm{cm})$ & 33.17 & & 0.01 & 33.19 & & 0.01 & $33 \cdot 21$ & & 0.01 & 33.19 & & 0.01 & 0.05 \\
\hline Chest circumference (cm) & $31 \cdot 78$ & & 0.01 & 31.80 & & 0.01 & 31.80 & & 0.01 & 31.78 & & 0.01 & 0.48 \\
\hline Ponderal index $\left(\mathrm{kg} / \mathrm{m}^{3}\right)$ & 25.85 & & 0.02 & $25 \cdot 78$ & & 0.02 & $25 \cdot 79$ & & 0.02 & $25 \cdot 74$ & & 0.02 & 0.001 \\
\hline
\end{tabular}

* Mean values with their standard errors were adjusted for maternal age (continuous), education (junior high school/high school, higher professional school/vocational school/junior college or university/graduate school), household income $\left(<2,2-<4,4-<6\right.$ or $\geq 6$ million Japanese yen), height, prepregnancy BMl ( $<18.5,18.5-<25,25-<30$ or $\left.\geq 30 \mathrm{~kg} / \mathrm{m}^{2}\right)$, pregnancy weight gain $(<7,7-12$ or $>12 \mathrm{~kg})$, parity $(0,1$ or $\geq 2)$, smoking (never, stopped before or after knowing pregnancy, current) and alcohol consumption (never, former or current), mother's thyroid disease (yes or no), use of folate supplement (yes or no), offspring sex (boy or girl) and gestational age (continuous) according to the quartiles of nutrients after log transformation.

† To convert energy values from kcal to kJ multiply by $4 \cdot 184$.

not birth length or head circumference, especially in women with high BMI in low-income countries ${ }^{(20)}$. On the other hand, a German study showed that the mother's intake of vitamins was not associated with their newborn's birth weight ${ }^{(33)}$. To the contrary, a study in New Zealand has shown that higher intakes of vitamin B during pregnancy were inversely associated with the birth size of winter born offspring ${ }^{(30)}$ and a Chinese study reported that folate intake during pregnancy was inversely associated with the offspring's birth weight ${ }^{(36)}$.

The huge discrepancies in the results of the studies that composed the previous literature on the one hand, and between findings of our study and those from the previous studies on the other hand can be attributed to the large differences in the population culture, characteristics and dietary habits, sample sizes, adjustment for maternal and offspring characteristics and tools used for dietary assessment. Therefore, with the large sample size of our study, the use of a validated FFQ that covered almost all the common and uncommonly consumed foods and beverages, and the adjustment of maternal and offspring characteristics, we believe that the generalisability of our study findings to the Japanese population is plausible. Yet, with the unique low dietary intakes of pregnant Japanese women, even before pregnancy, the generalisability of the findings to other populations cannot be guaranteed. Meanwhile, despite the significant differences in the outcome variables across the nutrients' categories, the absolute values of these differences are minimal and might lack clinical meaning in the neonatal field. However, such small significant changes in the birth size parameters were also reported in the previous studies $^{(10,13,17)}$. Moreover, the proportions of offspring with low birth weight, $<2500 \mathrm{~g}$ across the quartiles of maternal total energy intake in our study, were $8.4 \%$ in $\mathrm{Q} 1,7.6 \%$ in $\mathrm{Q} 2$, $7 \cdot 2 \%$ in Q3 and $7 \cdot 1 \%$ in Q4; $P_{\text {for trend }}<0 \cdot 001$. Other limitations of the current study include the possibility of multicollinearity of 
Table 5. Associations of maternal intakes of vitamins during pregnancy with the offspring's birth size (Mean values with their standard errors)

\begin{tabular}{|c|c|c|c|c|c|c|c|c|c|c|c|c|c|}
\hline & \multicolumn{12}{|c|}{ Quartiles of vitamin intakes } & \multirow[b]{3}{*}{$P_{\text {trend }}$} \\
\hline & \multicolumn{3}{|c|}{ Q1 } & \multicolumn{3}{|c|}{ Q2 } & \multicolumn{3}{|c|}{ Q3 } & \multicolumn{3}{|c|}{ Q4 } & \\
\hline & Mean & & SE & Mean & & SE & Mean & & SE & Mean & & SE & \\
\hline Vitamin A ( $\mu \mathrm{g} / 1000 \mathrm{kcal})$ & 136 & & & 212 & & & 289 & & & 545 & & & \\
\hline No. of participants & & 19698 & & & 19698 & & & 19699 & & & 19698 & & \\
\hline Birth weight $(\mathrm{g})$ & 3026 & & $2 \cdot 0$ & 3034 & & $2 \cdot 0$ & 3036 & & $2 \cdot 0$ & 3033 & & $2 \cdot 0$ & 0.01 \\
\hline Birth length (cm) & 48.94 & & 0.01 & $48 \cdot 96$ & & 0.01 & 48.97 & & 0.01 & $48 \cdot 97$ & & 0.01 & 0.16 \\
\hline Head circumference $(\mathrm{cm})$ & $33 \cdot 18$ & & 0.01 & $33 \cdot 20$ & & 0.01 & $33 \cdot 22$ & & 0.01 & $33 \cdot 17$ & & 0.01 & 0.004 \\
\hline Chest circumference $(\mathrm{cm})$ & $31 \cdot 76$ & & 0.01 & $31 \cdot 80$ & & 0.01 & $31 \cdot 81$ & & 0.01 & $31 \cdot 78$ & & 0.01 & 0.02 \\
\hline Ponderal index $\left(\mathrm{kg} / \mathrm{m}^{3}\right)$ & $25 \cdot 77$ & & 0.02 & $25 \cdot 81$ & & 0.02 & $25 \cdot 80$ & & 0.02 & $25 \cdot 77$ & & 0.02 & 0.29 \\
\hline Vitamin K ( $\mu \mathrm{g} / 1000 \mathrm{kcal})$ & 49 & & & 80 & & & 112 & & & 193 & & & \\
\hline No. of participants & & 19698 & & & 19698 & & & 19699 & & & 19698 & & \\
\hline Birth weight (g) & 3029 & & $2 \cdot 0$ & 3030 & & $2 \cdot 0$ & 3034 & & $2 \cdot 0$ & 3037 & & $2 \cdot 0$ & 0.05 \\
\hline Birth length (cm) & $48 \cdot 89$ & & 0.01 & 48.94 & & 0.01 & 48.99 & & 0.01 & 49.02 & & 0.01 & $<0.001$ \\
\hline Head circumference $(\mathrm{cm})$ & $33 \cdot 18$ & & 0.01 & $33 \cdot 19$ & & 0.01 & $33 \cdot 20$ & & 0.01 & $33 \cdot 20$ & & 0.01 & 0.45 \\
\hline Chest circumference (cm) & 31.79 & & 0.01 & $31 \cdot 78$ & & 0.01 & 31.80 & & 0.01 & $31 \cdot 78$ & & 0.01 & 0.56 \\
\hline Ponderal index $\left(\mathrm{kg} / \mathrm{m}^{3}\right)$ & $25 \cdot 88$ & & 0.02 & $25 \cdot 79$ & & 0.02 & $25 \cdot 75$ & & 0.02 & $25 \cdot 73$ & & 0.02 & $<0.001$ \\
\hline Vitamin $\mathrm{E}(\mathrm{mg} / 1000 \mathrm{kcal})$ & $2 \cdot 4$ & & & $3 \cdot 2$ & & & $3 \cdot 8$ & & & $5 \cdot 0$ & & & \\
\hline No. of participants & & 19694 & & & 19702 & & & 19698 & & & 19699 & & \\
\hline Birth weight (g) & 3028 & & $2 \cdot 0$ & 3033 & & $2 \cdot 0$ & 3038 & & $2 \cdot 0$ & 3030 & & $2 \cdot 0$ & 0.02 \\
\hline Birth length (cm) & 48.94 & & 0.01 & 48.95 & & 0.01 & 48.99 & & 0.01 & 48.96 & & 0.01 & 0.20 \\
\hline Head circumference $(\mathrm{cm})$ & $33 \cdot 18$ & & 0.01 & $33 \cdot 19$ & & 0.01 & $33 \cdot 21$ & & 0.01 & $33 \cdot 17$ & & 0.01 & 0.02 \\
\hline Chest circumference (cm) & 31.78 & & 0.01 & $31 \cdot 79$ & & 0.01 & $31 \cdot 81$ & & 0.01 & 31.78 & & 0.01 & 0.14 \\
\hline Ponderal index $\left(\mathrm{kg} / \mathrm{m}^{3}\right)$ & $25 \cdot 79$ & & 0.02 & $25 \cdot 80$ & & 0.02 & $25 \cdot 80$ & & 0.02 & $25 \cdot 76$ & & 0.02 & 0.25 \\
\hline Vitamin D ( $\mu \mathrm{g} / 1000 \mathrm{kcal})$ & 0.9 & & & $2 \cdot 0$ & & & 2.9 & & & 4.9 & & & \\
\hline No. of participants & & 19698 & & & 19699 & & & 19697 & & & 19699 & & \\
\hline Birth weight (g) & 3029 & & $2 \cdot 0$ & 3034 & & $2 \cdot 0$ & 3038 & & $2 \cdot 0$ & 3038 & & $2 \cdot 0$ & 0.006 \\
\hline Birth length (cm) & 48.93 & & 0.01 & 48.98 & & 0.01 & $48 \cdot 98$ & & 0.01 & 48.94 & & 0.01 & 0.02 \\
\hline Head circumference $(\mathrm{cm})$ & $33 \cdot 17$ & & 0.01 & $33 \cdot 21$ & & 0.01 & $33 \cdot 19$ & & 0.01 & $33 \cdot 19$ & & 0.01 & 0.05 \\
\hline Chest circumference $(\mathrm{cm})$ & $31 \cdot 78$ & & 0.01 & $31 \cdot 79$ & & 0.01 & $31 \cdot 82$ & & 0.01 & $31 \cdot 77$ & & 0.01 & 0.007 \\
\hline Ponderal index $\left(\mathrm{kg} / \mathrm{m}^{3}\right)$ & $25 \cdot 80$ & & 0.02 & $25 \cdot 78$ & & 0.02 & $25 \cdot 80$ & & 0.02 & $25 \cdot 78$ & & 0.02 & 0.74 \\
\hline Vitamin C (mg/1000 kcal) & 23 & & & 38 & & & 53 & & & 85 & & & \\
\hline No. of participants & & 19698 & & & 19699 & & & 19697 & & & 19699 & & \\
\hline Birth weight (g) & 3023 & & $2 \cdot 0$ & 3032 & & $2 \cdot 0$ & 3038 & & $2 \cdot 0$ & 3036 & & $2 \cdot 0$ & $<0.001$ \\
\hline Birth length (cm) & $48 \cdot 91$ & & 0.01 & 48.97 & & 0.01 & $48 \cdot 98$ & & 0.01 & $48 \cdot 98$ & & 0.01 & $<0.001$ \\
\hline Head circumference $(\mathrm{cm})$ & $33 \cdot 18$ & & 0.01 & $33 \cdot 20$ & & 0.01 & $33 \cdot 19$ & & 0.01 & $33 \cdot 19$ & & 0.01 & 0.55 \\
\hline Chest circumference $(\mathrm{cm})$ & $31 \cdot 78$ & & 0.01 & $31 \cdot 79$ & & 0.01 & $31 \cdot 81$ & & 0.01 & $31 \cdot 78$ & & 0.01 & 0.02 \\
\hline Ponderal index $\left(\mathrm{kg} / \mathrm{m}^{3}\right)$ & $25 \cdot 80$ & & 0.02 & $25 \cdot 77$ & & 0.02 & $25 \cdot 80$ & & 0.02 & $25 \cdot 79$ & & 0.02 & 0.58 \\
\hline Vitamin $\mathrm{B}_{6}(\mathrm{mg} / 1000 \mathrm{kcal})$ & 0.4 & & & 0.5 & & & 0.6 & & & 0.8 & & & \\
\hline No. of participants & & 19698 & & & 19699 & & & 19698 & & & 19698 & & \\
\hline Birth weight (g) & 3029 & & $2 \cdot 0$ & 3034 & & $2 \cdot 0$ & 3035 & & $2 \cdot 0$ & 3032 & & $2 \cdot 0$ & 0.23 \\
\hline Birth length (cm) & 48.93 & & 0.01 & 48.98 & & 0.01 & $48 \cdot 97$ & & 0.01 & 48.96 & & 0.01 & 0.02 \\
\hline Head circumference $(\mathrm{cm})$ & $33 \cdot 20$ & & 0.01 & $33 \cdot 19$ & & 0.01 & $33 \cdot 20$ & & 0.01 & $33 \cdot 18$ & & 0.01 & 0.55 \\
\hline Chest circumference (cm) & 31.79 & & 0.01 & $31 \cdot 80$ & & 0.01 & $31 \cdot 80$ & & 0.01 & 31.77 & & 0.01 & 0.33 \\
\hline Ponderal index $\left(\mathrm{kg} / \mathrm{m}^{3}\right)$ & $25 \cdot 82$ & & 0.02 & $25 \cdot 77$ & & 0.02 & $25 \cdot 79$ & & 0.02 & $25 \cdot 78$ & & 0.02 & 0.30 \\
\hline Folate ( $\mu \mathrm{g} / 1000 \mathrm{kcal})$ & 93 & & & 126 & & & 154 & & & 217 & & & \\
\hline No. of participants & & 19698 & & & 19698 & & & 19697 & & & 19700 & & \\
\hline Birth weight (g) & 3027 & & $2 \cdot 0$ & 3035 & & $2 \cdot 0$ & 3036 & & $2 \cdot 0$ & 3032 & & $2 \cdot 0$ & 0.03 \\
\hline Birth length (cm) & 48.91 & & 0.01 & 48.97 & & 0.01 & 48.98 & & 0.01 & 48.97 & & 0.01 & $<0.001$ \\
\hline Head circumference $(\mathrm{cm})$ & $33 \cdot 19$ & & 0.01 & $33 \cdot 20$ & & 0.01 & $33 \cdot 19$ & & 0.01 & $33 \cdot 18$ & & 0.01 & 0.47 \\
\hline Chest circumference $(\mathrm{cm})$ & 31.79 & & 0.01 & $31 \cdot 80$ & & 0.01 & $31 \cdot 78$ & & 0.01 & $31 \cdot 78$ & & 0.01 & 0.71 \\
\hline Ponderal index $\left(\mathrm{kg} / \mathrm{m}^{3}\right)$ & $25 \cdot 83$ & & 0.02 & $25 \cdot 79$ & & 0.02 & $25 \cdot 78$ & & 0.02 & $25 \cdot 76$ & & 0.02 & 0.09 \\
\hline Vitamin $B_{12}(\mu \mathrm{g} / 1000 \mathrm{kcal})$ & 1.0 & & & $1 \cdot 8$ & & & 2.5 & & & $4 \cdot 0$ & & & \\
\hline No. of participants & & 19699 & & & 19696 & & & 19700 & & & 19698 & & \\
\hline Birth weight (g) & 3028 & & $2 \cdot 0$ & 3033 & & $2 \cdot 0$ & 3036 & & $2 \cdot 0$ & 3032 & & $2 \cdot 0$ & 0.08 \\
\hline Birth length (cm) & 48.94 & & 0.01 & 48.96 & & 0.01 & 48.99 & & 0.01 & 48.94 & & 0.01 & 0.02 \\
\hline Head circumference $(\mathrm{cm})$ & $33 \cdot 17$ & & 0.01 & $33 \cdot 20$ & & 0.01 & $33 \cdot 20$ & & 0.01 & $33 \cdot 20$ & & 0.01 & 0.13 \\
\hline Chest circumference (cm) & 31.78 & & 0.01 & $31 \cdot 79$ & & 0.01 & 31.80 & & 0.01 & $31 \cdot 78$ & & 0.01 & 0.43 \\
\hline Ponderal index $\left(\mathrm{kg} / \mathrm{m}^{3}\right)$ & $25 \cdot 78$ & & 0.02 & $25 \cdot 79$ & & 0.02 & $25 \cdot 77$ & & 0.02 & $25 \cdot 82$ & & 0.02 & 0.22 \\
\hline
\end{tabular}

* Mean values with their standard errors were adjusted for maternal age (continuous), education (junior high school/high school, higher professional school/vocational school/junior college or university/graduate school), household income $\left(<2,2-<4,4-<6\right.$ or $\geq 6$ million Japanese yen), height, prepregnancy BMl ( $<18.5,18.5-<25,25-<30$ or $\left.\geq 30 \mathrm{~kg} / \mathrm{m}^{2}\right)$, pregnancy weight gain $(<7,7-12$ or $>12 \mathrm{~kg}$ ), parity $(0,1$ or $\geq 2)$, smoking (never, stopped before or after knowing pregnancy, current) and alcohol consumption (never, former or current), mother's thyroid disease (yes or no), use of folate supplement (yes or no), offspring sex (boy or girl) and gestational age (continuous) according to the quartiles of nutrients after log transformation. 
the maternal intakes of nutrients because of common dietary sources. Thus, the contribution of other unstudied maternal dietary factors towards the offspring's birth size cannot be excluded. The observed associations depended mainly on early- to mid-pregnancy dietary intakes that were measured once, at the time of the second/third trimester questionnaire. Dietary intakes could have changed throughout pregnancy; however, some studies have not only shown that measuring the maternal diet in early pregnancy is important for various organs' differentiation and development ${ }^{(3,12,18-20)}$, but also indicated that dietary intakes are likely to be relatively constant throughout pregnancy ${ }^{(37,38)}$. Moreover, the same FFQ was distributed to the same cohort of women in our study in the first trimester asking about the previous 1-year intakes and showed similar low dietary intakes than the Japanese dietary recommended intakes.

\section{Conclusion}

In summary, dietary intakes of energy, macronutrients and vitamins among Japanese pregnant women were associated with the offspring's birth size. The offspring's birth weight was related mainly to maternal intakes of total energy, dietary fibre and vitamins A, K, E, D, C and folate, whereas the birth length was related to maternal carbohydrates, total fibre, vitamins $\mathrm{K}, \mathrm{C}, \mathrm{D}, \mathrm{B}_{6}, \mathrm{~B}_{12}$ and folate intakes. Accordingly, the ponderal index, a proxy for the offspring's overall adiposity, was inversely associated with maternal carbohydrates, total fibre and vitamin $\mathrm{K}$ intakes. Head circumference was positively associated with vitamins $\mathrm{A}, \mathrm{E}$ and $\mathrm{D}$ intakes, while chest circumference was associated mainly with the mother's intake of vitamins A, D and C. These findings could help postulate the pregnancy dietary guidelines to prevent unfavourable birth size of the Japanese women's offspring.

\section{Acknowledgements}

We are grateful to all participants who have taken part in the JECS. We would like to also thank all staff members of the JECS. Members of the Japan Environment and Children's Study (JECS) as of 2019 (principal investigator, Michihiro Kamijima): Shin Yamazaki (National Institute for Environmental Studies, Tsukuba, Japan), Yukihiro Ohya (National Center for Child Health and Development, Tokyo, Japan), Reiko Kishi (Hokkaido University, Sapporo, Japan), Nobuo Yaegashi (Tohoku University, Sendai, Japan), Koichi Hashimoto (Fukushima Medical University, Fukushima, Japan), Chisato Mori (Chiba University, Chiba, Japan), Shuichi Ito (Yokohama City University, Yokohama, Japan), Zentaro Yamagata (University of Yamanashi, Chuo, Japan), Hidekuni Inadera (University of Toyama, Toyama, Japan), Michihiro Kamijima (Nagoya City University, Nagoya, Japan), Takeo Nakayama (Kyoto University, Kyoto, Japan), Hiroyasu Iso (Osaka University, Suita, Japan), Masayuki Shima (Hyogo College of Medicine, Nishinomiya, Japan), Youichi Kurozawa (Tottori University, Yonago, Japan), Narufumi Suganuma (Kochi University, Nankoku, Japan), Koichi Kusuhara (University of Occupational and Environmental
Health, Kitakyushu, Japan) and Takahiko Katoh (Kumamoto University, Kumamoto, Japan).

This study was funded and supported by the Ministry of the Environment, Japan. The findings and conclusions of this article are solely the responsibility of the authors and do not represent the official views of the above government agency.

The authors' contributions were as follows: H. I. and Japan Environment and Children's Study Group designed the research, E. S. E. and C. O. conducted the analyses and prepared the manuscript; H. I., S. B., T. K., S. I., T. S. and K. S. made critical revisions of the manuscript; E. S. E. and H. I. had primary responsibility for final content. All authors read and approved the manuscript.

The authors declare that there are no conflicts of interest.

\section{Supplementary material}

For supplementary material referred to in this article, please visit https://doi.org/10.1017/S0007114520001397

\section{References}

1. Chen LW, Tint MT, Fortier MV, et al. (2016) Maternal macronutrient intake during pregnancy is associated with neonatal abdominal adiposity: the Growing Up in Singapore Towards healthy Outcomes (GUSTO) Study. J Nutr 146, 1571-1579.

2. Chen X, Zhao D, Mao X, et al. (2016) Maternal dietary patterns and pregnancy outcome. Nutrients $\mathbf{8}$, E351.

3. Moore VM, Davies MJ, Willson KJ, et al. (2004) Dietary composition of pregnant women is related to size of the baby at birth. J Nutr 134, 1820-1826.

4. Kubota K, Itoh H, Tasaka M, et al. (2013) Changes of maternal dietary intake, bodyweight and fetal growth throughout pregnancy in pregnant Japanese women. J Obstet Gynaecol Res 39, $1383-1390$.

5. Cnattingius S, Villamor E, Lagerros YT, et al. (2012) High birth weight and obesity: a vicious circle across generations. Int $J$ Obes 36, 1320-1324.

6. Goto Y (2006) Diseases in the 21st century. JJap Soc Stud Obes 12, $1-2$.

7. Mother's and Children's Health and Welfare Association (2011) Maternal and Child Status of Japan 2011. Tokyo: Mother's and Children's Health Organization (In Japanese).

8. Hayashi F, Takimoto H, Yoshita K, et al. (2006) Perceived body size and desire for thinness of young Japanese women: a population-based survey. Br J Nutr 96, 1154-1162.

9. Takimoto H, Yoshiike N, Katagiri A, et al. (2003) Nutritional status of pregnant and lactating women in Japan: a comparison with non-pregnant/non-lactating controls in the National Nutrition Survey. J Obstet Gynaecol Res 29, 96-103.

10. Okubo H, Miyake Y, Sasaki S, et al. (2011) Nutritional adequacy of three dietary patterns defined by cluster analysis in 997 pregnant Japanese women: the Osaka Maternal and Child Health Study. Public Health Nutr 14, 611-621.

11. Bouwland-Both MI, Steegers-Theunissen RP, Vujkovic M, et al. (2013) A periconceptional energy-rich dietary pattern is associated with early fetal growth: the Generation R study. BJOG 120, 435-445.

12. Mathews F, Yudkin P \& Neil A (1999) Influence of maternal nutrition on outcome of pregnancy: prospective cohort study. BMJ 319, 339-343.

13. Chong MF, Chia AR, Colega M, et al. (2015) Maternal protein intake during pregnancy is not associated with offspring 
birth weight in a multiethnic Asian population. J Nutr 145 , 1303-1310.

14. Langley-Evans AJ \& Langley-Evans SC (2003) Relationship between maternal nutrient intakes in early and late pregnancy and infants weight and proportions at birth: prospective cohort study. J R Soc Promot Health 123, 210-216.

15. Godfrey K, Robinson S, Barker DJ, et al. (1996) Maternal nutrition in early and late pregnancy in relation to placental and fetal growth. BMJ 312, 410-414.

16. Sloan NL, Lederman SA, Leighton J, et al. (2001) The effect of prenatal dietary protein intake on birth weight. Nutr Res 21, 129-139.

17. Durrani AM \& Rani A (2011) Effect of maternal dietary intake on the weight of the newborn in Aligarh city, India. Niger Med J52, $177-181$.

18. Gernand AD, Schulze KJ, Stewart CP, et al. (2016) Micronutrient deficiencies in pregnancy worldwide: health effects and prevention. Nat Rev Endocrinol 12, 274-289.

19. Grieger JA \& Clifton VL (2014) A review of the impact of dietary intakes in human pregnancy on infant birthweight. Nutrients $\mathbf{7}$, 153-178.

20. Fall CH, Fisher DJ, Osmond C, et al. (2009) Maternal micronutrient Supplementation Study Group. Multiple micronutrient supplementation during pregnancy in low-income countries: a meta-analysis of effects on birth size and length of gestation. Food Nutr Bull 30, Suppl. 4, S533-S546.

21. Michikawa T, Nitta H, Nakayama SF, et al. (2018) Baseline profile of participants in the Japan Environment and Children's Study (JECS). J Epidemiol 28, 99-104.

22. Kawamoto T, Nitta H, Murata K, et al. (2014) Rationale and study design of the Japan Environment and Children's Study (JECS). BMC Public Health 14, 25.

23. Yokoyama Y, Takachi R, Ishihara J, et al. (2016) Validity of short and long self-administered food frequency questionnaires in ranking dietary intake in middle-aged and elderly Japanese in the Japan Public Health Center-Based Prospective Study for the Next Generation (JPHC-NEXT) protocol area. J Epidemiol 26, 420-432.

24. Science and Technology Agency (2000) Standard Tables of Food Composition in Japan, 5th rev. ed. Tokyo: Printing Bureau, Ministry of Finance (in Japanese).

25. Yokoyama T (2012) Infant Physical Development: Evaluation Manual. Statistical Analysis of Infant Physical Development Survey, Research on its Method and Utilization (In Japanese). https://www.niph.go.jp/soshiki/07shougai/hatsuiku/index.files/ katsuyou_130805.pdf (accessed July 2019).
26. Ministry of Health, Labour and Welfare, Japan (2017) Dietary References Intakes for Japanese 2015. http://www.mhlw.go. jp/file/06-Seisakujouhou-10900000-Kenkoukyoku/Overview. pdf (accessed July 2017).

27. Sasaki S (2008) Dietary Reference Intakes (DRIs) in Japan. Asia Pac J Clin Nutr 17, Suppl. 2, 420-444.

28. Tsukamoto H, Fukuoka H, Inoue K, et al. (2007) Restricting weight gain during pregnancy in Japan: a controversial factor in reducing perinatal complications. Eur J Obstet Gynecol Reprod Biol 133, 53-59.

29. Weigel MM, Nárváez WM, López A, et al. (1991) Prenatal diet, nutrient intake and pregnancy outcome in urban Ecuadorian primiparas. Arch Latinoam Nutr 41, 21-37.

30. Watson PE \& McDonald BW (2007) Seasonal variation of nutrient intake in pregnancy: effects on infant measures and possible influence on diseases related to season of birth. Eur J Clin Nutr 61, 1271-1280.

31. Abu-Saad K \& Fraser D (2010) Maternal nutrition and birth outcomes. Epidemiol Rev 32, 5-25.

32. Imhoff-Kunsch B, Briggs V, Goldenberg T, et al. (2012) Effect of $\mathrm{n}-3$ long-chain polyunsaturated fatty acid intake during pregnancy on maternal, infant, and child health outcomes: a systematic review. Paediatr Perinat Epidemiol 26, Suppl. 1, 91-107.

33. Diemert A, Lezius S, Pagenkemper M, et al. (2016) Maternal nutrition, inadequate gestational weight gain and birth weight: results from a prospective birth cohort. BMC Pregnancy Childbirth 16, 224.

34. Okubo H, Miyake Y, Sasaki S, et al. (2012) Maternal dietary patterns in pregnancy and fetal growth in Japan: the Osaka Maternal and Child Health Study. Br J Nutr 107, 1526-1533.

35. Zhang W (2013) The influence of maternal nutrition intake on the birth weight of newborns in Lanzhou, China. Public Health Thesis, Yale University. http://elischolar.library.yale.edu/ ysphtdl/1341/ (accessed July 2019).

36. Hajhoseini L (2013) Importance of optimal fiber consumption during pregnancy. Int J Women's Health Reprod Sci $\mathbf{1}$, 66-69.

37. Cuco G, Fernandez-Ballart J, Sala J, et al. (2006) Dietary patterns and associated lifestyles in preconception, pregnancy and postpartum. Eur J Clin Nutr 60, 364-371.

38. Crozier SR, Robinson SM, Godfrey KM, et al. (2009) Women's dietary patterns change little from before to during pregnancy. J Nutr 139, 1956-1963. 